\title{
STUDIO EPIDEMIOLOGICO E OTTIMIZZAZIONE DI REAL-TIME PCR PER L'IDENTIFICAZIONE DI ADENOVIRUS IN CAMPIONI CLINICI.
}

\author{
La Rosa' G., Muscillo' M, Di Grazia' A., Fontana' S., \\ De Carolis² E.,. Sali M, Manzara² S. and Fadda² G. \\ 'Istituto Superiore di Sanità, Roma. \\ 2 Policlinico A. Gemelli, Università Cattolica "S. Cuore", Roma.
}

Introduzione. Gli Adenovirus sono un gruppo estremamente eterogeneo e diffuso di virus, spesso associati ad epidemie influenzali. In Italia non esistono dati sulla loro circolazione nell'uomo né sono stati proposti metodi per la loro determinazione qualitativa e quantitativa.

Metodi. In questo lavoro, una collezione di 103 isolati clinici proveniente dall' Università Cattolica del Sacro Cuore di Roma costituita da tamponi fecali (71\%), faringei (25\%), liquor $(1 \%)$, urine $(2 \%)$ e materiale bioptico (1\%) inoculati su cellule Vero o Hep2, è stata inizialmente identificata mediante immunofluorescenza. Successivamente i DNA estratti da lisati cellulari sono stati amplificati mediane PCR avente come target il gene "hexon". L'analisi delle sequenze degli amplificati ha rivelato che tutte le specie da $\mathrm{A}$ ad $\mathrm{F}$ sono presenti in Italia e che la specie $\mathrm{C}$ ha una prevalenza del $77 \%$ con i sierotipi $2(53,4 \%), 1(15,6 \%)$ e $6(8,7 \%)$.

L'amplicone del sierotipo 2 è stato clonato in plasmide pCR4-TOPO e lo stock plasmidico utilizzato per la calibrazione di una RealTime PCR.

Una curva di calibrazione è stata ottenuta con diluizioni scalari in base 10 di uno stock contenente 25 picogrammi $/ \mathrm{ml}$ $\left(4.46 \times 10^{9}\right.$ genome $\left./ \mathrm{ml}\right)$ di plasmide. Una seconda curva di calibrazione è stata ottenuta con diluizioni scalari di adenovirus 2 da $1,22 \times 10^{-2}$ a $5,59 \mathrm{CCID}_{50} / \mathrm{ml}$. Il segnale fluorescente, ottenuto con lo stesso probe su tutti i sierotipi della collezione, è stato determinato usando il metodo TaqMan ed apparecchiatura $\mathrm{ABI} 7000$.

Risultati. Il doppio sistema di calibrazione ha permesso di stabilire un rapporto medio genomi/particelle infettanti pari a $8,12 \times 10^{5}$. Questo parametro ha permesso di dedurre che la concentrazione delle particelle infettanti nei campioni di lisati originari variava da 10 a $10^{3} \mathrm{CCID}_{50} / \mathrm{ml}$ e che la soglia di sensibilità del metodo è di $10^{-4}-10^{-5} \mathrm{CCID}_{50} / \mathrm{ml}$. Come controlli positivi sono stati utilizzate soluzioni titolate di Adenovirus 40 e 41 dell'ATCC.

Conclusioni. La sensibilità e caratteristiche del protocollo lo rendono applicabile all'identificazione e quantificazione di adenovirus direttamente in campioni clinici. 